\title{
Anti-Hypertensive Effects of Blended Camellia oleifera Abel Oil and Eucommia Extract on SHR Mice
}

\author{
Menghao Du, Lisong Hu, Xuezhi Fang, Jingping Zhang \\ Research Institute of Subtropical Forestry, Chinese Academy of Forestry, Fuyang, China \\ Email: xiaoduchongcn@aliyun.com
}

How to cite this paper: $\mathrm{Du}, \mathrm{M}$. H., Hu, L. S., Fang, X. Z., \& Zhang, J. P. (2020). Anti-Hypertensive Effects of Blended Camellia oleifera Abel Oil and Eucommia Extract on SHR Mice. Open Journal of Forestry, 10, $1-6$.

https://doi.org/10.4236/ojf.2020.101001

Received: October 25, 2019

Accepted: November 25, 2019

Published: November 28, 2019

Copyright () 2020 by author(s) and Scientific Research Publishing Inc. This work is licensed under the Creative Commons Attribution International License (CC BY 4.0).

http://creativecommons.org/licenses/by/4.0/

\begin{abstract}
In our study, we employed Camellia seed oil as the main ingredients blended with Eucommia Extract to investigate the effects of anti-hypertensive on mice by administrating mice with low dose, middle dose and high dose of Camellia seed oil complex for 4 weeks. The specific tests of studying effects of anti-hypertensive were body weight, blood systolic pressure (BSP), diastolic blood pressure (DBP), pm meam blood pressure (MBP) and heart rate (HR). And the results showed that appropriate level of Camellia seed oil complex could decrease the body weight and had an active effect on the cardiovascular system of mice, which significantly embodied the anti-hypertensive activity of Camellia seed oil complex.
\end{abstract}

\section{Keywords}

Camellia Seed Oil, Eucommia Extract, Anti-Hypertensive, Mice

\section{Introduction}

Camellia (Camellia oleiferous Abel.) seed oil is unique woody oil in China which is widely used in south of China as edible oil, medicine and burning injury for thousands of years. It has high nutritional value and has been considered a popular healthy food because it mainly composed of unsaturated fatty acids and a small amount of saturated fatty acids. Furthermore, it contains a considerable numbers of bioactive phytochemicals such as phytosterols, squalenes and tocopherol. Its fatty acid composition is similar to olive oil, which known as the "queen of vegetable oil" (Xiao, 2015). The content of unsaturated fatty acid is over $90 \%$, oleic acid is up to $80 \%$ (Zhu et al., 2012; Dong, 2011; Chen, 2011) and some nutrients are even higher than olive oil (Zhong et al., 2006). The Camellia 
seed oil is applied as functional food and food supplementary to help patients reduce contents of cholesterol and triglycerides in blood (Lee \& Yen, 2006; Fedeli et al., 1966). Zhang and Zhou et al. reported that tea oil had antioxidant ability against several degenerative pathologies, including cardiovascular diseases and cancer (Zhang \& Zhou, 1995). Moreover, the Camellia seed oil was shown to have an anti-obesity effect in vivo model. However, little information has been devoted to the anti-fatigue effects of the tea seed oil.

The extract of eucommia ulmoides had higher chlorogenic acid (Zang, 1989) and chlorogenic acid has a variety of pharmacological effects such as cholagogic, antibacterial, antiviral, anti-hypertensive, raising white blood cells and stimulating the central nervous system (Zhang et al., 2001). So it is an important raw material for health care, food, medicine, cosmetics and other industries.

Our goal is to evaluate the effect of anti-hypertensive activity of the complex of Camellia seed oil blended Eucommia extract in mice. And we will evaluate the possibility of Camellia seed oil blended Eucommia extract as human daily food in next studying.

\section{Materials and Methods}

\subsection{Materials}

Tea seed oil from Camellia oleifera Abel was obtained by cold-press technique from Jiande Xiawu Agriculture Development Co., Ltd., Zhejiang, China.

Eucommia Extracts were purchased from Qingdao New Research Nonferrous Metal Co., Ltd., Qingdao, China.

Tea seed oil complex: adding the tea seed oil and Eucommia Extract, with the ratio of $(100: 1)$, at $30^{\circ} \mathrm{C}-70^{\circ} \mathrm{C}$ in a flask, the mixture was stirred fiercely with T25 digital ultra-turrax high-speed homogenizer, IKA Co., Germany, till the tea seed oil and Eucommia Extract distributed well and keep at $4^{\circ} \mathrm{C}$ in refrigerator.

Solvent: Sucrose fatty acid esters were purchased from Mitsubishi Corporation of Japan. Adding $2 \%$ sucrose fatty acid esters in $1000 \mathrm{ml}$ distilled water $\left(98^{\circ} \mathrm{C}\right)$, the mixture was stirred fiercely with T25 digital ultraturrax high-speed homogenizer, IKA Co., Germany, till the mixture was distributed well and cooled down.

\subsection{Animals}

SHR mice (SPF Grade, male, 10 weeks old) and Wistar mice (SPF Grade, male, 10weeks old) were purchased from Shanghai slack laboratory animal Co. Ltd. (SCXK (Hu) 2007-0005). All animal procedures performed were in accordance with the standard Guidelines for Animal Studies and approved by the Institutional Animal Ethics Committee.

\subsection{Methods}

After being fed for 20 days, 50 male SHR mice were divided into 4 groups randomly according to their basic blood pressure and body weights. one group named model control group (MCG) was supplemented with $10 \mathrm{ml} \cdot \mathrm{kg}^{-1}$ solvent 
$\mathrm{day}^{-1}$ by oral intake in the food, the other three group named low dose group (LDG), middle dose group (MDG) and high dose group (HDG) were administrated $0.5,1.0$ and $2.0 \mathrm{~g} \cdot \mathrm{kg}^{-1} \cdot \mathrm{day}^{-1}$ of tea seed oil complex by oral intake respectively. 10 male Wistar mice as normal control group (NCG) was administrated $10 \mathrm{ml} \cdot \mathrm{kg}^{-1}$ solvent day ${ }^{-1}$ by oral intake. Mice were performed the weight test, blood pressure measurement and heart rate test at the 0 week, $1^{\text {st }}$ week, $2^{\text {nd }}$ week, $3^{\text {rd }}$ weeks and $4^{\text {th }}$ weeks.

\subsection{Condition}

Mice were housed in SPF Laboratory maintained at $22^{\circ} \mathrm{C} \pm 1^{\circ} \mathrm{C}, 50 \%-70 \%$ humidity and $150-200 \mathrm{Lx}$ intensity of light with a $12 \mathrm{~h}$ light/dark cycle. 60 mice were randomly divided into polycarbonate cages. 5 mice in each set allowed free access to eat and drink water. The water was filtered and sterilized. And the feed was radioactive by Co 60 to sterilize.

\subsection{Instrument}

ALC-NIBP Noninvasive blood pressure measurement system of rat tail artery, Shanghai Alcott biotechnology Co., Ltd.

MLS-3020 High pressure sterilizer, Sanyo electronics Co., Ltd. of Japan.

AG204 Alectronic analytical balance METTLER Co., Ltd. of Swiss land.

\subsection{Data Statistics}

Data were analyzed using SPSS 11.5 version (SPSS Inc., Chicago, IL, USA). The results were demonstrated as the mean $\pm \mathrm{S}$. The significance of the mean difference between the control groups and each treatment group was performed by one-way AVOVA test.

\section{Result}

\subsection{Different Treatment Groups Body Weight}

Comparing with NCG, MCG the initial body weight was significantly higher than that of NCG $(P<0.01)$, however, after feeding 3 weeks, MCG the body weight was significantly lower than that of NCG $(P<0.05)$. LDG, MDG and HDG comparing with MCG, there was no significant change in body weight $(P>0.05)$ after feeding 4 weeks (Table 1$)$.

Table 1. Different treatment groups body weight (g, $n=10, \bar{X} \pm s)$.

\begin{tabular}{|c|c|c|c|c|c|c|}
\hline Group & Doseage & Initial Weight & 1 Week & 2 Week & 3 Week & 4 Week \\
\hline NCG & $10 \mathrm{ml} \cdot \mathrm{kg}^{-1}$ solvent & $311.0 \pm 11.5$ & $346.4 \pm 12.6$ & $358.5 \pm 18.3$ & $374.3 \pm 20.0$ & $375.9 \pm 20.5$ \\
\hline MCG & $10 \mathrm{ml} \cdot \mathrm{kg}^{-1}$ solvent & $337.9 \pm 20.0^{\Delta \Delta}$ & $352.2 \pm 20.3$ & $354.3 \pm 20.1$ & $352.4 \pm 21.3^{\Delta}$ & $354.8 \pm 23.0^{\Delta}$ \\
\hline LDG & $0.5 \mathrm{~g} \cdot \mathrm{kg}^{-1}$ oil & $344.5 \pm 15.3$ & $359.7 \pm 15.3$ & $363.9 \pm 14.4$ & $365.7 \pm 16.8$ & $366.7 \pm 17.8$ \\
\hline MDG & $1.0 \mathrm{~g} \cdot \mathrm{kg}^{-1} \mathrm{oil}$ & $331.7 \pm 18.6$ & $341.6 \pm 18.8$ & $345.0 \pm 17.2$ & $350.3 \pm 17.2$ & $350.0 \pm 18.7$ \\
\hline HDG & $2.0 \mathrm{~g} \cdot \mathrm{kg}^{-1} \mathrm{oil}$ & $339.3 \pm 27.2$ & $351.5 \pm 25.5$ & $358.4 \pm 24.1$ & $362.2 \pm 18.8$ & $359.0 \pm 16.8$ \\
\hline
\end{tabular}

Significantly different from the normal control group, ${ }^{\Delta} P<0.05,{ }^{\Delta \Delta} P<0.01$; Significantly different from the model control group, ${ }^{\star} P<0.05,{ }^{* \star} P<0.01$. 


\subsection{Effects of Tea Seed Oil Complex on BSP of Mice}

Comparing with NCG, the blood systolic pressure (BSP) of MDG was significantly higher than that of NCG in 4 weeks test $(P<0.01)$. Comparing with MCG, the BSP of HDG decreased significantly after feeding 2,3 and 4 weeks $(P$ $<0.05, P<0.01)$, the BSP of MDG decreased significantly after feeding 2 and 4 weeks $(P<0.05, P<0.01)$, the BSP of LDG decreased significantly after feeding 2 weeks $(P<0.05)$ (Table 2$)$.

\subsection{Effects of Tea Seed Oil Complex on DBP of Mice}

Comparing with NCG, the diastolic blood pressure (DBP) of MDG was significantly higher than that of NCG in 4 weeks test $(P<0.01)$. Comparing with MCG, the DBP of HDG decreased significantly after feeding 2,3 and 4 weeks $(P$ $<0.05, P<0.01)$, the DBP of MDG decreased significantly after feeding 2 and 4weeks $(P<0.05, P<0.01)$, the DBP of LDG decreased significantly after feeding 2 weeks $(P<0.05)$ (Table 3$)$.

\subsection{Effects of Tea Seed Oil Complex on MBP of Mice}

Comparing with NCG, the pm meam blood pressure (MBP) of MDG was significantly higher than that of NCG in 4 weeks test $(P<0.01)$. Comparing with MCG, the MBP of HDG decreased significantly after feeding 2, 3 and 4 weeks $(P<0.05, P<0.01)$, the MBP of MDG decreased significantly after feeding 2 and 4 weeks $(P<0.05, P<0.01)$, the MBP of LDG decreased significantly after feeding 2 weeks $(P<0.05)$ (Table 4$)$.

Table 2. Effects of tea seed oil complex on BSP of mice (mmHg, $n=10, \quad \bar{X} \pm s$ ).

\begin{tabular}{|c|c|c|c|c|c|c|}
\hline Group & Doseage & Initial BSP & 1 Week & 2 Week & 3 Week & 4 Week \\
\hline NCG & $10 \mathrm{ml} \cdot \mathrm{kg}^{-1}$ solvent & $136.6 \pm 18.2$ & $134.3 \pm 22.2$ & $133.5 \pm 22.5$ & $144.5 \pm 8.8$ & $145.4 \pm 10.3$ \\
\hline MCG & $10 \mathrm{ml} \cdot \mathrm{kg}^{-1}$ solvent & $192.5 \pm 10.5^{\Delta \Delta}$ & $183.1 \pm 8.5^{\Delta \Delta}$ & $209.8 \pm 2.4^{\Delta \Delta}$ & $204.0 \pm 6.8^{\Delta \Delta}$ & $216.3 \pm 5.1^{\Delta \Delta}$ \\
\hline LDG & $0.5 \mathrm{~g} \cdot \mathrm{kg}^{-1}$ oil & $192.0 \pm 10.4$ & $181.3 \pm 19.8$ & $197.0 \pm 15.2^{\star}$ & $199.9 \pm 14.2$ & $207.8 \pm 10.7$ \\
\hline MDG & $1.0 \mathrm{~g} \cdot \mathrm{kg}^{-1}$ oil & $191.0 \pm 12.5$ & $182.3 \pm 17.0$ & $191.2 \pm 12.1^{\star \star}$ & $202.6 \pm 11.4$ & $205.0 \pm 12.2^{\star}$ \\
\hline HDG & $2.0 \mathrm{~g} \cdot \mathrm{kg}^{-1}$ oil & $192.8 \pm 15.2$ & $173.0 \pm 23.7$ & $186.2 \pm 12.1^{\star *}$ & $195.9 \pm 7.0^{\star}$ & $190.9 \pm 18.3^{* *}$ \\
\hline
\end{tabular}

Significantly different from the normal control group, ${ }^{\Delta} P<0.05,{ }^{\Delta \Delta} P<0.01$; Significantly different from the model control group, ${ }^{\star} P<0.05,{ }^{\star *} P<0.01$.

Table 3. Effects of tea seed oil complex on DBP of mice (mmHg, $n=10, \bar{X} \pm s$ ).

\begin{tabular}{|c|c|c|c|c|c|c|}
\hline Group & Doseage & Initial DBP & 1 Week & 2 Week & 3 Week & 4 Week \\
\hline NCG & $10 \mathrm{ml} \cdot \mathrm{kg}^{-1}$ solvent & $102.8 \pm 15.0$ & $101.6 \pm 19.5$ & $101.9 \pm 17.4$ & $109.3 \pm 7.2$ & $107.6 \pm 7.7$ \\
\hline LDG & $0.5 \mathrm{~g} \cdot \mathrm{kg}^{-1}$ oil & $143.0 \pm 10.4$ & $136.5 \pm 10.7$ & $147.2 \pm 10.4^{\star}$ & $149.8 \pm 9.6$ & $153.0 \pm 5.9$ \\
\hline MDG & $1.0 \mathrm{~g} \cdot \mathrm{kg}^{-1}$ oil & $143.0 \pm 11.3$ & $136.1 \pm 12.8$ & $140.6 \pm 7.7^{\star \star}$ & $147.4 \pm 9.0$ & $149.5 \pm 8.9^{*}$ \\
\hline $\mathrm{HDG}$ & $2.0 \mathrm{~g} \cdot \mathrm{kg}^{-1} \mathrm{oil}$ & $142.4 \pm 13.8$ & $128.4 \pm 15.7$ & $139.9 \pm 13.0^{\star *}$ & $144.7 \pm 5.6^{*}$ & $140.3 \pm 12.1^{\star *}$ \\
\hline
\end{tabular}

Significantly different from the normal control group, ${ }^{\Delta} P<0.05,{ }^{\Delta \Delta} P<0.01$; Significantly different from the model control group, ${ }^{\star} P<0.05,{ }^{\star *} P<0.01$. 


\subsection{Effects of Tea Seed Oil Complex on HR of Mice}

Comparing with NCG, the heart rate (HR) of MDG was significantly higher than that of NCG in 4 weeks test $(P<0.05, P<0.01)$. However, comparing with MCG, there was no significant change in HR $(P>0.05)$ between LDG, MDG and HDG to MCG after feeding 4 weeks (Table 5).

\section{Discussion and Conclusion}

The initial body weight of MCG was heavier than that of NCG, however, the body weight of MCG was lighter than that of NCG after 3 weeks feeding (Table 1). It suggested that Camellia seed oil blended Eucommia extract has the function of control body weight. In fact, obesity can lead to serious health issues, like cardiovascular disease (Wang et al., 2014). Furthermore, the complex of Camellia seed oil blended Eucommia extract can decrease BSP, DBP, MBP and HR (Tables 2-5). Our results demonstrated that the complex of Camellia seed oil blended Eucommia extract did good things to the cardiovascular system of SHRmice. The reason is that Camellia seed oil contained a great deal of unsaturated fatty acid (Oleic acid $>80 \%, \omega 9$ ) and micronutrient (phytosterols, squalenes and tocopherol) (Zhong et al., 2006). Oleic Acid Protects from Arsenic-Induced Cardiac Hypertrophy via AMPK/FoxO/NFATc3 Pathway (Samanta et al., 2019).

In conclusion, our results suggest that Camellia seed oil complex had significant anti-hypertensive effects on mice and these effects were dose-dependent. When dosage was high, it normally would improve the effects much better.

Table 4. Effects of tea seed oil complex on MBP of mice (mmHg, $n=10, \bar{X} \pm s$ ).

\begin{tabular}{|c|c|c|c|c|c|c|}
\hline Group & Doseage & Initial MBP & 1 Week & 2 Week & 3 Week & 4 Week \\
\hline NCG & $10 \mathrm{ml} \cdot \mathrm{kg}^{-1}$ solvent & $114.0 \pm 15.8$ & $112.5 \pm 20.3$ & $112.4 \pm 19.0$ & $121.0 \pm 7.4$ & $120.2 \pm 8.3$ \\
\hline MCG & $10 \mathrm{ml} \cdot \mathrm{kg}^{-1}$ solvent & $159.8 \pm 9.4^{\Delta \Delta}$ & $153.2 \pm 9.1^{\Delta \Delta}$ & $174.0 \pm 4.3^{\Delta \Delta}$ & $170.8 \pm 6.9^{\Delta \Delta}$ & $177.8 \pm 6.3^{\Delta \Delta}$ \\
\hline LDG & $0.5 \mathrm{~g} \cdot \mathrm{kg}^{-1}$ oil & $159.3 \pm 10.0$ & $151.5 \pm 13.5$ & $163.8 \pm 11.8^{*}$ & $166.5 \pm 10.9$ & $171.3 \pm 6.8$ \\
\hline MDG & $1.0 \mathrm{~g} \cdot \mathrm{kg}^{-1}$ oil & $159.0 \pm 11.2$ & $151.5 \pm 13.3$ & $157.5 \pm 8.8^{\star \star}$ & $165.8 \pm 9.6$ & $167.6 \pm 9.4^{*}$ \\
\hline HDG & $2.0 \mathrm{~g} \cdot \mathrm{kg}^{-1}$ oil & $159.2 \pm 13.7$ & $143.3 \pm 18.2$ & $155.3 \pm 12.3^{* *}$ & $161.8 \pm 5.8^{\star}$ & $157.1 \pm 13.7^{\star *}$ \\
\hline
\end{tabular}

Significantly different from the normal control group, ${ }^{\Delta} P<0.05,{ }^{\Delta \Delta} P<0.01$; Significantly different from the model control group, ${ }^{\star} P<0.05,{ }^{* *} P<0.01$.

Table 5. Effects of tea seed oil complex on HR of mice (bpm, $n=10, \bar{X} \pm s$ ).

\begin{tabular}{|c|c|c|c|c|c|c|}
\hline Group & Doseage & Initial HR & 1 Week & 2 Week & 3 Week & 4 Week \\
\hline NCG & $10 \mathrm{ml} \cdot \mathrm{kg}^{-1}$ solvent & $379.0 \pm 39.7$ & $371.3 \pm 52.0$ & $355.8 \pm 40.5$ & $343.4 \pm 23.5$ & $332.5 \pm 21.7$ \\
\hline LDG & $0.5 \mathrm{~g} \cdot \mathrm{kg}^{-1}$ oil & $425.6 \pm 49.8$ & $422.0 \pm 37.2$ & $429.3 \pm 39.8$ & $424.6 \pm 31.6$ & $437.5 \pm 31.9$ \\
\hline MDG & $1.0 \mathrm{~g} \cdot \mathrm{kg}^{-1}$ oil & $405.9 \pm 34.0$ & $431.9 \pm 20.9$ & $414.0 \pm 35.3$ & $443.9 \pm 27.2$ & $417.8 \pm 42.7$ \\
\hline HDG & $2.0 \mathrm{~g} \cdot \mathrm{kg}^{-1}$ oil & $439.0 \pm 37.4$ & $445.8 \pm 36.2$ & $428.5 \pm 35.4$ & $443.4 \pm 21.3$ & $419.9 \pm 40.5$ \\
\hline
\end{tabular}

Significantly different from the normal control group, ${ }^{\Delta} P<0.05,{ }^{\Delta \Delta} P<0.01$; Significantly different from the model control group, ${ }^{\star} P<0.05,{ }^{\star \star} P<0.01$. 


\section{Acknowledgements}

This work was supported by the project of Science and Technology Department of Zhejiang Province, China (2017C02003).

\section{Conflicts of Interest}

The authors declare that they have no competing interests.

\section{References}

Chen, X. Y. (2011). Comparative Study on Three Methods for the Extraction of Oil from Camellia Seed. Northwest Agriculture and Forestry University.

Dong, J. Y. (2011). Research of Consumer Buying Behavior of Tea-Seed Oil Based on the Value Cognition. Fujian Agriculture and Forestry University.

Fedeli, E., Lanzani, A., Capella, P., \& Jacini, G. (1966). Triterpene Alcohols and Sterols of Vegetable Oils. Journal of the American Oil Chemists' Society, 43, 254-256. https://doi.org/10.1007/BF02641098

Lee, C. P., \& Yen, G. C. (2006). Antioxidant Activity and Bioactive Compounds of Tea Seed (Camellia oleifera Abel.) Oil. Journal of Agricultural and Food Chemistry, 54, 779-784. https://doi.org/10.1021/jf052325a

Samanta, J., Mondal, A., Saha, S., Chakraborty, S., \& Sengupta, A. (2019). Oleic Acid Protects from Arsenic-Induced Cardiac Hypertrophy via AMPK/FoxO/NFATc3 Pathway. Cardiovascular Toxicology, 1-20. https://doi.org/10.1007/s12012-019-09550-9

Wang, Z. W., Hao, G., Wang, X., Chen, Z., Zhang, L. F., Guo, M., Tian, Y., Shao, L., Zhu, M. L., \& Wu, K. G. (2014). Current Prevalence Rates of Overweight, Obesity, Central Obesity, and Related Cardiovascular Risk Factors that Clustered among Middle-Aged Population of China. Chinese Journal of Hypertension, 22, 1000.

Xiao, Y. P. (2015). Research of Unsaponifiable Substances in Tea Seed Oil and Camellia Oleifera Seed Oil. Nanchang University, Jiangxi, China.

Zang, Y. W. (1989). Advances in Chemical Constituents of Eucommia Ulmoides. Chinese Traditional and Herbal Drugs, 20, 42-44.

Zhang, A. L., Ma, Q., Gao, J. M., Zhang, K. J., \& Wang, L. (2001). Studies on Bioactivities of Chlorogenic Acid and Itsanalogues. Chinese Traditional and Herbal Drugs, 2, 79-82.

Zhang, B., \& Zhou, Y. (1995). Effects of Tea Seed Oil and Soybean Oil on Oxygen Radical and Activities of Antioxidative Enzymes in Rat. Acta Nutrimenta Sinica, 17, 1432-1338.

Zhong, H. Y., Bedgood, D. R., Bishop, A. G., Prenziler, P. D., \& Pobards, K. (2006). Effect of Added Caffeic Acid and Tyrosol on the Fatty Acid and Volatile Profiles of Camellia Oil Following Heating. Journal of Agricultural and Food Chemistry, 54, 9551-9558. https://doi.org/10.1021/jf061974z

Zhu, Y., Zhong, H. Y., Sun, H. Z., Zhou, B., Long, Q. Z., \& Zhu, P. (2012). Development of Quantitative Analysis of Fatty Acid for Monitoring Changes of Fatty Acid Profile of Camellia Oil. Advanced Materials Research, 554-556, 1202-1210. https://doi.org/10.4028/www.scientific.net/AMR.554-556.1202 